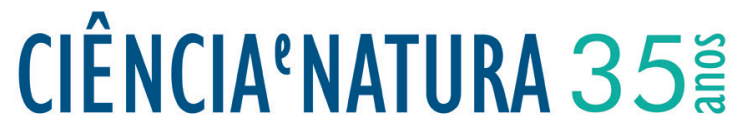

\section{Uma descoberta que mudou a forma de pensar ou como a ciência muda a humanidade}

\author{
A discovery that changed the way we think \\ or how science changes humanity
}

\section{Mario Norberto Baibich ${ }^{1}$}

${ }^{1}$ Instituto de Física, Universidade Federal do Rio Grande do Sul, Porto Alegre, Brasil

\begin{abstract}
Resumo
A partir da observação das mudanças introduzidas pela descoberta científica (no caso, a magnetorresistência gigante, de que participamos), tentamos retraçar os desenvolvimentos tecnológicos dos últimos anos. Mesmo sem apelar para conhecimento específico profundo, podemos mostrar como aconteceu a mudança em nossos hábitos por conta da mudança tecnológica e associar como se muda a humanidade a partir da ciência bem feita.
\end{abstract}

Palavras-chave: Magnetorresistência Gigante, Desenvolvimento tecnológico, Descoberta Científica.

\begin{abstract}
Starting from the observation of the changes introduced by scientific discovery (specifically, giant magnetoresistance, that we participated), we try to retrace the technological development of late. Even without using advanced specific knowledge of the field, we can show how the changes in our everyday life happened as a result of technological revolution and understand how humanity is changed by good science.
\end{abstract}

Keywords: Giant Magnetoresistance, Technological Development, Scientific Discovery. 


\section{Introdução}

$\mathrm{P}$ or trás de toda mudança de hábitos na humanidade, procure bem, muito provavelmente houve antes uma invenção, uma mudança de paradigma. E, assim, uma nova forma de ver o Mundo.

Nós, que fomos privados de assistir às grandes transformações trazidas pela roda ou pelo fogo, podemos hoje olhar mais de perto a mudança trazida por uma descoberta de que participamos. O que tentarei mostrar no que segue é uma aproximação tosca ao estudo epistemológico que deveria ser feito (e certamente o será). Deixo isso, então, aos especialistas; eu me atenho às observações de um visitante casual.

Em 1988 estivemos envolvidos numa das belas descobertas que acontecem na vida de todo cientista. Na ocasião, mesmo sem ter a dimensão do que viria a ser a Magnetorresistência Gigante, brincávamos no laboratório tentando ver qual das amostras "a gente vende pros americanos". Devo dizer que foi, de alguma maneira, premonitório de tudo o que se sucedeu. O que quero focar neste breve ensaio é justamente o que sucedeu (e segue!) à sensação de fazer uma descoberta, por menor que seja a percepção que tínhamos dela no momento.

Lembro de todas as descobertas que fiz na vida, desde os logaritmos antes da professora ensinar em aula até as de anteontem: a vida de um cientista é sempre marcada por pequenas descobertas, talvez só interessantes para duas ou três pessoas no planeta, mas essenciais para nos manter curiosos e maravilhados com o que fazemos. Algumas dessas pequenas descobertas se tornam grandes e extrapolam nossos meios mais próximos, viram substantivos comuns nas áreas correlatas e acabam (algumas, pelo menos) agraciadas com prêmios e fama.

Um número menor dentre essas termina premiada com o que é considerado o topo do mundo: o Premio Nobel. Nossa descoberta de 1988 acabou sendo agraciada com o Nobel de Física de 2007. Ou seja, se tornou uma das 107 pesquisas premiadas dos últimos 113 anos.

Não como consequência do Premio Nobel, mas como causa deste, tivemos uma mini-revolução dos conceitos, uma dessas revoluções científicas de que fala Kuhn [1].

Imagine-se agora sem seu smartphone, sem os muitos gigabytes (ou até terabytes) no seu disco rígido, sem "streaming" de imagens, sem Google na internet (ou mesmo sem internet!)... Tudo isso é resultado dos avanços que aconteceram como consequência da ciência que fizemos, nós, cientistas de todo o mundo, e continuamos fazendo. Foram descobertas científicas que acabaram chegando às ruas de todo o planeta, entrando na vida dos mais ricos aos mais pobres, dos mais sábios aos menos esclarecidos.

\section{$2 \mathrm{Um}$ pouco de história, mesmo que vaga}

Em 1986, um grupo liderado pelo Prof. Peter Grünberg (em Jülich, Alemanha) verificou que, ao construir estruturas em forma de filmes alternados de material magnético e não magnético, obtinham o que hoje se chama de Antiferromagneto Artificial.

Nas experiências realizadas em Jülich, Alemanha, quando se fazia um "sanduíche" de ferro com "recheio" de cromo, o que se via era o alinhamento dentro de cada camada de ferro exatamente igual ao que se observa em um pedaço de grandes dimensões de ferro: interação ferromagnética, o que significa que todos os momentos magnéticos atômicos apontam aproximadamente para o mesmo sentido.

Só que, para espessuras pequenas de cromo (o recheio do sanduíche), da ordem de um nanometro (10-9 metros, um milionésimo de milímetro, ou 3 a 4 átomos empilhados), a orientação da camada de ferro de baixo do sanduiche ficava consistentemente ao contrário da orientação da camada de ferro de cima do sanduiche. A esse fenômeno de interação entre as camadas (ferromagnéticas) de baixo e de cima através do separador (o recheio, no caso reportado em 1986, de cromo [2]) se associou a denominação de "Acoplamento Antiparalelo". (veja a figura 1)

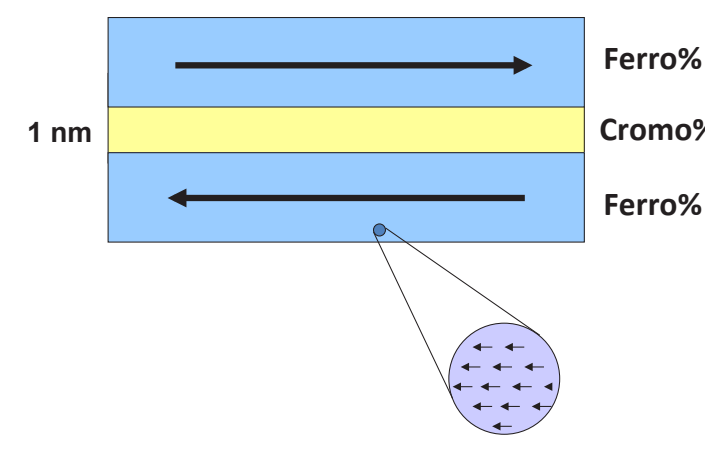

a.

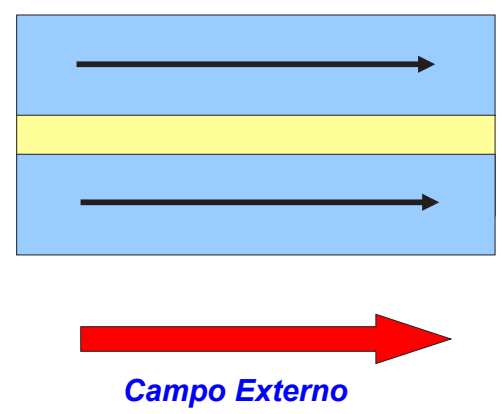

b.

Figura 1 a. Sem campo magnético aplicado o sistema se alinha antiferromagneticamente (orientações contrárias), mas cada camada tem ordem ferromagnética, como no detalhe ampliado; $b$. com campo magnético externo aplicado ambos os lados do sanduíche se orientam paralelo ao campo externo (ferromagneticamente). 
Mais tarde, o mesmo fenômeno foi observado numa série de composições similares, com as camadas externas do sanduíche de material ferromagnético ( $\mathrm{como} \mathrm{Fe}, \mathrm{Co}$, $\mathrm{Ni}$ etc.) e a camada de separação (o recheio) de material não magnético (como cobre ou prata, por exemplo).

Em 1988, o grupo do Prof. Albert Fert (do qual fiz parte nesse mesmo ano de 1988), na Université de Paris Sud (Université de Paris XI - Orsay), estudava exatamente o mesmo sistema por conta das possibilidades que se viam nas propriedades magnéticas desse arranjo.

A partir da ideia de aumentar a quantidade de material magnético das amostras, o que facilitaria as medidas, $\mathrm{o}$ grupo optou por construir multicamadas dos mesmos materiais. Isso significa que tínhamos uma "pilha de sanduiches" (veja a figura 2), onde se queria observar o acoplamento antiparalelo com medidas essencialmente magnéticas, o que funcionou maravilhosamente bem.

\begin{tabular}{|l|}
\hline ferromagnético! \\
\hline não magnético \\
\hline ferromagnético! \\
\hline não magnético \\
\hline ferromagnético! \\
\hline não magnético \\
\hline ferromagnético! \\
\hline
\end{tabular}

Figura 2: Multicamada Magnética

Com isso, uma boa quantidade de medidas desses sistemas foi sendo acumulada e serviu, mais adiante, para fazer o papel de base experimental para as teorias que foram sugeridas na literatura.

Vem, então, o que classifico como uma boa pergunta: o que vai acontecer ao elétron quando passar de uma camada orientada para outra? A resposta não tardou a chegar, mas tivemos alguns meses de trabalho incessante para que fosse possível entender o que estava ocorrendo.

Na primeira experiência feita para medir a magnetorresistência (a mudança da resistência elétrica como resultado de aplicar um campo magnético) destas amostras multicamadas, vimos a resistência da amostra cair a praticamente à metade (perto de $50 \%$ ) do valor sem campo aplicado.

Isso era totalmente inesperado para metais, já que os valores habituais da mudança de resistência promovida pela aplicação de um campo magnético não passavam de 3 ou $4 \%$ [3].

Muitas tentativas depois (com o mesmo resultado), já que queríamos descartar a possibilidade de algum artefato na nossa experiência provocar o que parecia um curto-circuito, trocamos a amostra por outra do mesmo tipo, mas com espessura de separador diferente. Aí sim, nos convencemos que tínhamos um resultado interessantíssimo e digno de nota. Foi aí que começamos a brincadeira sobre "vender aos americanos".

Algumas reuniões locais e internacionais depois de termos começado a entender o que acontecia, escrevemos com a máxima urgência (em plenas férias do Laboratório, na França, que virtualmente para no mês de agosto!) um artigo que acabou sendo publicado na conceituada revista especializada Physical Review Letters [4]. Esse artigo tem, hoje, mais de 5450 citações em revistas de circulação internacional.

\section{Duas correntes}

Naquele artigo, meio contra minha opinião mais comedida, falou-se pela primeira vez no termo Magnetorresistência Gigante (GMR, da sigla em inglês) para descrever o fenômeno da mudança importante da resistência elétrica por alinhamento de camadas que tínhamos visto.

Nos dias de hoje se usa esse termo toda vez que o mecanismo que gera a mudança na resistência da amostra ao aplicar um campo magnético é atribuído ao alinhamento de duas (ou mais) regiões ferromagnéticas da amostra em estudo (com isto, hoje se fala sem problemas de uma GMR com valores da ordem de $1 \%$, ou até menos!).

O medo que tínhamos ao medir a magnetorresistência das amostras naquelas primeiras experiências era que estivéssemos medindo, realmente, um curto-circuito em algum lugar do sistema de medidas. O que se viu, mais tarde, foi que o temido curto-circuito estava, na realidade, dentro da amostra!

Eu explico: quando se considera o transporte eletrônico num material ferromagnético, temos de considerar a interação do spin do elétron (sua característica magnética) com os núcleos atômicos do material, o que resulta em espalhamento (que é o que determina a condutividade ou a resistividade do material). Ao fazer o espalhamento de elétrons com spins diferentes, cada camada ferromagnética espalha fortemente aqueles spins que estão antiparalelos com a sua orientação magnética.

Olhando a Figura 3a, na situação sem campo aplicado, quando o alinhamento entre duas camadas é antiparalelo,

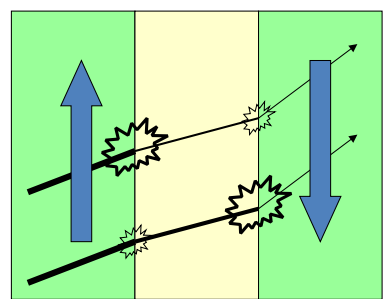

a

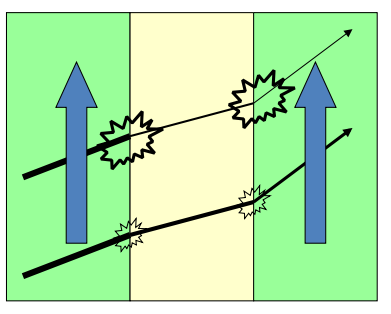

b
Figura 3: a. Sem campo magnético aplicado; b. com campo magnético externo aplicado. 
o elétron com spin "certo" para a primeira camada será muito espalhada na seguinte. O mesmo raciocínio serve para os dois canais de spin (elétrons com spin "para baixo" ou "para cima"), o que fornece um espalhamento razoavelmente grande (resistência média).

Mas no caso de forçarmos o alinhamento das camadas por meio da aplicação de um campo magnético (relativamente) forte, como na Figura 3b, o que se vê é uma diferença significativa entre um canal e outro. Para o spin com orientação contrária à orientação das camadas ferromagnéticas, que acompanham o sentido ditado pelo grande campo magnético externo, o espalhamento será grande em cada uma das interfaces que ele visitar.

Já para o spin "bem comportado" (com a mesma orientação das camadas magnéticas e do campo externo), a situação é completamente diferente. Como o elétron tem spin "favorável", o espalhamento nas interfaces que visitar será pequeno, criando assim um "curto-circuito" dentro da amostra! (Veja a figura $3 b$ ).

A ideia de usar este fenômeno para ler campos muito pequenos surgiu naturalmente, já que todos estavam conscientes das exigências do mercado de gravação magnética, seja para uso em computadores ou em televisão de alta definição (que era o objetivo "de ouro" da indústria eletrônica na época - quem tivesse o melhor sistema estabeleceria um padrão ao qual todos se adaptariam, como foi o caso do CD ou fita cassete e tantos outros).

O problema era que, no caso em que trabalhamos originalmente, os campos necessários para observar o fenômeno eram enormes (entre 2 e 5 Tesla; equivalente a cerca de 10.000 vezes o campo magnético terrestre médio no Rio Grande do Sul! [5]).

\section{$4 \mathrm{O}$ uso do fenômeno}

As ideias de como fazer para conseguir usar esse conceito não tardaram a chegar. Pouco tempo depois da descoberta do efeito da GMR, uma nova forma de "ler" campos minúsculos surgiu: a "Válvula de Spin".

Este dispositivo aplica o mesmo conceito do espalhamento dependente de spin a camadas também nanoscópicas, mas com características ferromagnéticas ligeiramente diferentes entre si.

Usando uma das características de qualquer camada ou mesmo peça ferromagnética, seu "Campo Coercivo", foram feitos sanduiches com as camadas ferromagnéticas (de fora) de espessuras ligeiramente diferentes, ou então de composição e espessura diferentes.

Com isso, a inversão de uma camada em relação à outra depende só da diferença entre os campos coercivos de cada camada. E ajustar esse campo coercivo é assunto bem conhecido na literatura do Magnetismo há muito tempo.

Desta forma, um pequeno campo é suficiente para fazer girar a magnetização das camadas do estado original antiparalelo ao paralelo. Isto é exatamente o que se precisa para "ler" a informação gravada numa fita ou disco magnético.

As aplicações desse conceito cresceram vertiginosamente no período, inundando todas as possíveis aplicações de leitura de campo magnético, como em sistemas de frenagem controlada, gerenciamento de funcionamento de motores automotivos, controle de funcionamento de marca-passos e muitas outras.

Mas a maior "sacudida" aconteceu no ramo da gravação magnética: ao obter sensores mais eficientes (um campo menor era necessário para gerar uma diferença apreciável na leitura), o campo necessário para "escrever" uma informação pôde ser reduzido e, assim, a densidade de gravação pôde ser aumentada, e muito!

Pouco a pouco toda a indústria de discos rígidos foi conquistada, de modo a que qualquer disco rígido com capacidade maior que $15 \mathrm{~Gb}$ usa o conceito da GMR ou similares.

Com o tempo esta tecnologia foi aprimorada e por fim substituída por Magnetorresistência Túnel (TMR), que é um parente próximo da GMR, eis que usa o mesmo conceito da orientação de camadas paralelas ou antiparalelas para variar a resistência do dispositivo. No caso da TMR, o "separador", ao invés de uma camada metálica não-magnética, é feito de uma fina camada isolante.

Com isso a condução ocorre por "tunelamento quântico" (condução através de um não-condutor, ou isolante, o que é totalmente contra-intuitivo e resultado da Mecânica Quântica), tal como ocorre nos transistores e sistemas do gênero. $\mathrm{O}$ que se sabe é que o tunelamento é favorecido quando os contatos ferromagnéticos estão alinhados, justamente o conceito que se introduziu na indústria com a GMR.

Entre as muitas aplicações que surgiram nestes anos, voltamos a um ícone, o "iPod Classic" (Apple Computer, EUA), que foi lançado originalmente em 2001 e relançado em 2007 com um disco rígido de 160 Gb. Para a época, era uma capacidade inacreditável, quase um passe de mágica. O preço de lançamento do iPod Classic nos Estados Unidos era de 349 dólares em 2007, que se justificava pela enorme capacidade de guardar músicas ou até mesmo filmes.

Mas, se olharmos para o início dos anos 80 do século passado, facilmente se encontram ofertas de discos rígidos com capacidade de $10 \mathrm{Mb}$ por valores em torno dos 3400 dólares. Mesmo se esquecermos as correções monetárias necessárias para tornar comparáveis os preços de épocas diferentes (que tornariam ainda mais caros os preços dos discos rígidos daquela época), os $160 \mathrm{~Gb}$ do iPod Classic valeriam, só pelo dispositivo de armazenamento, cerca de US\$54.400.000!

A diferença entre o preço de 2007 e o dos discos rígidos dos anos 80 é pura tecnologia. Essa enorme diferença (preço 155874 vezes maior, considerando apenas o disco rígido dentro do iPod, o que representa um crescimento médio de $577300 \%$ ao ano), por inimaginável que pareça, poderá se repetir nos próximos anos. 
Muitos atribuem essa mudança radical no acesso às tecnologias disponíveis atualmente à Lei de Moore [6] (sobre os processadores, que dão ideia da capacidade de fazer contas de um circuito eletrônico).

Os que trabalham mais próximos do armazenamento magnético invocam o que hoje se conhece como a "Lei de Kryder" [7] (cunhada num artigo na Scientific American em 2005 sobre os achados de Mark Kryder, da Seagate Corp., a respeito do crescimento do armazenamento de longo prazo), que aponta para taxas ainda mais elevadas de crescimento (veja figura 4).

O que queremos dizer é que a influência do preço do armazenamento no sistema final tem sido maior que a do processamento. Ganhos na densidade de gravação e leitura tornaram mais acessíveis instrumentos como computadores, smartphones e tantos outros.

\section{Um Círculo Virtuoso}

Veja bem: com a Magnetorresistência Gigante, permitimos que áreas menores do disco rígido fossem utilizadas para gravação, já que havia tecnologia para distinguir áreas menores. Isto significa maior densidade de gravação, que se tornou maior capacidade e menor preço para os discos rígidos e que, por sua vez, fez com que novos programas pudessem ser implementados.

Isso gerou a necessidade de eletrônica mais rápida que, a seu turno, precisou de mais rapidez no acesso aos dados, o que permitiu com que mais programas existissem, que pediam (novamente) mais capacidade

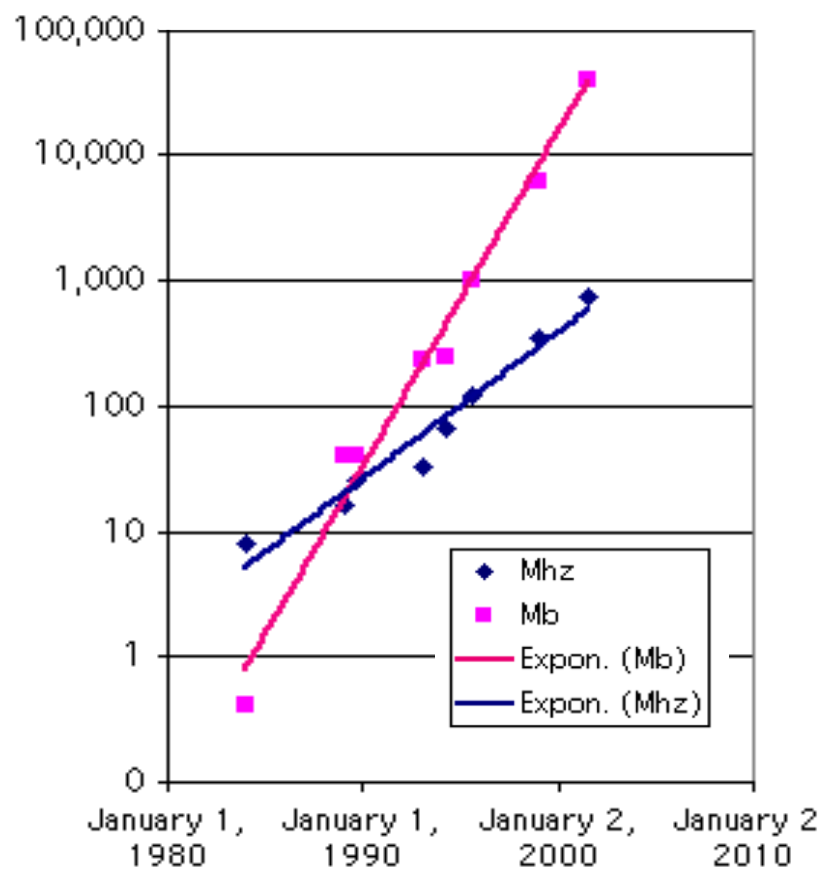

Figura 4: Leis de Moore [6] e de Kryder [7] (atenção: o eixo vertical é exponencial!) de armazenamento.

O resultado dessa espiral você conhece: é nossa sociedade de hoje, que não consegue mais se ver sem as facilidades que toda a informática moderna traz. Praticamente não conseguimos sobreviver sem o acesso rápido e universal aos bancos de dados, aos buscadores, ao editor de textos. Já não podemos mais nos imaginar sem tomografias computadorizadas ou imagens por ressonância magnética, contas no computador, e-mail, "Twitter", "facebook", "Skype", "nuvem de dados"...

Todas essas coisas são possíveis graças ao avanço que foi, em boa parte, desencadeado pela descoberta científica. Sim, essa mesma descoberta que derivou de uma pergunta essencial, como em qualquer pesquisa científica de valor. E a pergunta que nos fizemos à época da descoberta da Magnetorresistência Gigante só foi possível por ter havido, antes, outras pesquisas, outros resultados, de outros conceitos mais fundamentais

Foi com base em ciência de qualidade, em experiências em quantidade e com critério rigoroso que esta descoberta aconteceu. Nada teria resultado se não houvesse uma base científica para nos guiar, para nos levar ao próximo estágio. Engana-se quem julga que tecnologia é algo autossuficiente, que basta aprender como se faz (mesmo sem saber o por quê). Se não tivéssemos, nós e todos os que se aventuraram nesta empreitada, conhecimento sólido, confiável, a tecnologia jamais teria condições de fazer todos os "milagres" que foram feitos!

As ideias básicas que levaram à Magnetorresistência Gigante começaram nos anos 30 do século passado. Primeiro foi Sir Nevill Mott, lançando a ideia da independência no transporte dos elétrons de spin diferente dentro de um metal ferromagnético [3]. Mais tarde, Albert Fert e Ian Campbell escrevem seu artigo (resultado da tese de doutorado do primeiro, sob orientação do segundo) sobre a condução em metais ferromagnéticos usando o conceito das correntes independentes para cada spin [4], levando aos artigos que fizeram a base conceitual da área e que influenciaram um número expressivo de físicos ao redor do mundo, inclusive no nosso Instituto de Física da UFRGS.

O futuro científico de muitos de nossos pesquisadores estava traçado desde então: o transporte eletrônico em ferromagnetos iria acompanhar nossas vidas acadêmicas até agora... E a de muitos de nossos alunos! A disseminação dessa maneira de estudar a Física se repetiu na América Latina assim como o fora na Europa, América do Norte, Ásia...

\section{Chega a Spintrônica}

O avanço na compreensão dos fenômenos envolvendo o spin do elétron em regiões magnéticas permitiu que a Spintrônica pudesse acontecer. A Spintrônica é o resultado da junção da eletrônica tradicional, que considera apenas a carga do elétron, com a capacidade de distinguir 
o seu spin. Hoje em dia temos bilhões de dispositivos funcionando em discos rígidos para computadores, câmeras, iPods, televisores e outros aparelhos que sequer suspeitamos usam discos para armazenamento.

E esses bilhões (sim, são bilhões de unidades!) de aparelhos fizeram com que a sociedade como um todo passasse a esperar algo diferente como resposta a seus anseios, tornando obsoletas tantas e tantas tecnologias. Nós pertencemos a uma geração que "enterrou" muitas tecnologias. Lembra do fax? E do Telex, então? Ligações interurbanas sem discagem direta? Telefone com dial circular, quem sabe? Cartão de crédito com papeleta e carbono? Paro por aqui para não perder a atenção dos mais jovens, que nunca ouviram falar dessas tecnologias "pré-históricas".

É claro que tudo isso não foi consequência só da Magnetorresistência Gigante, mas ela foi parte importante na engrenagem que levou a este desenvolvimento vertiginoso.

O que temos agora é uma situação de transição para alçar voos mais ousados: usando a spintrônica mais amplamente podemos pensar em quebrar paradigmas até hoje intocáveis como, por exemplo, pensar em trocar a base da computação de 2 para 3, ampliando assim as possibilidades de explorar problemas mais complexos, ou então trabalhar com memórias RAM magnéticas não voláteis (que usam o mesmo princípio da GMR para ler junções gravadas magneticamente, já disponíveis no mercado, mas com preços ainda elevados).

O fato de ser não-volátil faz com que aquela chatice de ter de desligar (e religar no dia seguinte) o computador de maneira específica e demorada fosse eliminada, com a vantagem adicional de poder pensar em computação sem armazenamento de longo prazo (disco rígido ou outro tipo de memória de estado sólido).

Aliás, o próprio disco rígido parece ter seus dias contados: já estão em desenvolvimento sistemas de armazenamento mais eficientes do que a ultrapassada tecnologia eletromecânica, mesmo com toda a sofisticada tecnologia que faz o leitor do disco rígido "voar" a uma "altitude" de alguns nanometros (entre 6 e $8 \mathrm{~nm}$ - algo como 20 átomos empilhados!) acima do disco... e ao mesmo tempo ler toda a informação que está gravada. Para avaliar o grau de dificuldade, isto é equivalente a fazer voar um Airbus 380 (o maior avião comercial em operação nos dias de hoje) à velocidade de cruzeiro (entre 900 e $1000 \mathrm{~km} / \mathrm{h}$ ) a uma "altitude" de cerca de meio metro e, ao mesmo tempo, contar todas as folhinhas de grama que passam por baixo do avião!

A alternativa aos discos rígidos está, hoje em dia, limitada às memórias flash de grande capacidade, como nos modernos "Ultrabooks" (os mais comuns entre 128 e $512 \mathrm{~Gb}$ ).

Mas uma série de novidades está a caminho: Mais uma vez usando o caráter magnético do elétron (seu spin), como é o caso da "Racetrack Memory" [8].

\section{Mudança de Paradigma}

Essa invenção, vinda da mesma empresa que inventou o disco rígido (mas que há algum tempo vendeu seu departamento de produção dos mesmos, incluindo a equipe de pesquisadores e laboratórios de desenvolvimento) se baseia em usar uma corrente "polarizada em spin" (com a maioria de seus elétrons orientados num sentido específico) para fazer pequenos setores (domínios) de um nanofio "desfilarem" frente a um leitor similar ao usado atualmente no disco rígido.

Usando essa corrente polarizada é possível deslocar, sem alterar, os domínios que representam cada bit de informação. Em cada nanofio podem ser armazenados cerca de 30 domínios, o que requer apenas um transistor por nanofio. Apesar de contabilizar um número enorme de nanofios para escrever toda a informação desejada, isto é muito menor do que os modelos atuais para RAM magnética (MRAM). Neste panorama, a cada bit da MRAM corresponderia um transistor, o que é cerca de 30 vezes mais caro (no item transistores) do que a Racetrack Memory.

Menciono esta característica das MRAMs pois há algum tempo se pensava seriamente em dotar os computadores com uma memoria RAM não-volátil tão grande que dispensasse o uso de armazenamento de longo prazo (somente dedicado à memória "estática", como o disco rígido), inclusive com algumas empresas criando grupos de trabalho para estudar como ficaria a computação sem o tradicional disco rígido a que nos habituamos há tanto tempo.

Outro desenvolvimento surpreendente está relacionado aos chamados "Skyrmions" [9]. Skyrmions são excitações tipo vórtices de spins: numa região da amostra, por conta de interações spin-órbita, surgem perturbações estáveis que podem se mover com grande velocidade dentro do material. Estas "perturbações", então, podem ser usadas para transmitir (ou fazer desfilar, usando a terminologia da Racetrack Memory) as informações com uma fidelidade e capacidade de vencer obstáculos notável, o que qualifica o estudo dessas perturbações quânticas como de grande futuro

O que quero ressaltar é que, por mais que tenhamos uma tecnologia muito eficiente para os padrões de hoje, vamos precisar de saltos qualitativos como os apontados acima para atingir nossos objetivos mais ousados e alimentar nossos sonhos e os de toda a humanidade. Sonhos de mais justiça social conquistada com transparência, com acessibilidade universal, com possibilidades concretas de crescimento pessoal.

Se conseguimos mudar a descrição das funções do dedo polegar, reportado como mero auxiliar nas funções do dia a dia do homem até cerca de 20 ou 30 anos atrás, tornando-o essencial para operar videogames e celulares, por exemplo, creio que temos todas as condições de criar um novo mundo com outras perspectivas 
e outros costumes.

O papel da Ciência na Sociedade é tema de muitas e muitas teses e opiniões, mas inegavelmente temos algo transformador em mãos e devemos fazer o melhor uso possível de todas as potencialidades. Para isto, temos de ter a consciência de que o apoio à ciência, como dizia Mahatma Gandhi, não pode ser menosprezado pois é o motor das mudanças sociais que buscamos. O Brasil, como país emergente ou em desenvolvimento, não pode esquecer o quanto pode vir da Ciência bem feita. Os cidadãos formados em um ambiente onde a Ciência é valorizada aproveitarão os ensinamentos para crescer e florescer.

Conseguimos, como civilização, chegar até este ponto. Agora é tempo de passar a outro nível, onde o pensar será mudado como consequência de toda nossa história. O que quero deixar registrado é o exemplo de que, partindo de suposições feitas no intuito de achar um modelo para explicar o transporte eletrônico no caso dos metais ferromagnéticos, terminamos, décadas depois, com algo prático e útil, que mudou a forma com que a humanidade encara problemas, simples e complicados, de novo usando o conhecimento gerado na ciência bem feita.

\section{Referências}

1. Kuhn, T.; A estrutura das revoluções científicas. $7^{\mathrm{a}}$ ed. São Paulo: Perspectiva, (2003).

2. Grünberg, P.; Schreiber, R.; Pang, Y.; Brodsky, M. B.; Sowers, H.; Phys. Rev. Letters 57, 2442 (1986)

3. No caso de cristais superpuros com orientação muito bem definida, os chamados "whiskers", pode ser observada uma magnetorresistência enorme, mas isso era uma total exceção num laboratório habituado a medir policristais metálicos; na realidade, tínhamos preparado o equipamento para que fosse capaz de detectar variações da ordem de uma parte em um milhão $(0,0001 \%)$, o que era, na época, muito bom para medir magnetorresistências.

4. Baibich M. N., Broto J.M., Fert A., Nguyen Van Dau, F., Petroff, F.; Etienne, P.; Creuzet, G.; Friederich, A. and Chazelas J.; Phys. Rev. Letters 61, 2472 (1988)

5. Mott, N. F. and Jones, H., The Theory of Properties of Metals and Alloys (Dover Publications Inc., New York, 1958)

6. Fert, A. and Campbell, I. A.; Phys. Rev. Letters 21, 1190 (1968).
7. http://upload.wikimedia.org/wikipedia/ commons/c/c7/WMM2010_F_MERC.pdf; acesso em 19 jan 2014

8. http://www-03.ibm.com/ibm/history/ibm100/us/ en/icons/racetrack/; acesso em 19 jan 2014.

9. http://www.spacedaily.com/reports/Electric Current_Moves_Magnetic_Vortices_999.html; acesso em 19 jan 2014. 